\title{
Anti-infectious Effect of $S$-Benzylisothiourea Compound A22, Which Inhibits the Actin-Like Protein, MreB, in Shigella flexneri
}

\author{
Norihisa Noguchi, ${ }^{*, a}$ Keita Yanagimoto, ${ }^{a}$ Hidemasa Nakaminami, ${ }^{a}$ Moeru WaKabaYashi,${ }^{a}$ \\ Noritaka IwAI, ${ }^{b}$ Masaaki WACHI, ${ }^{b}$ and Masanori SASATSU ${ }^{a}$ \\ ${ }^{a}$ Department of Microbiology, School of Pharmacy, Tokyo University of Pharmacy and Life Science; 1432-1 Horinouchi, \\ Hachioji, Tokyo 192-0392, Japan: and ${ }^{b}$ Department of Bioengineering, Tokyo Institute of Technology; 4259 Nagatsuta, \\ Midori-ku, Yokohama 226-8503, Japan \\ Received January 18, 2008; accepted April 21, 2008; published online April 30, 2008
}

\begin{abstract}
$S$-Benzylisothiourea compound A22 induces coccoid forms in Escherichia coli by inhibiting the function of the actin-like cytoskeletal protein, MreB. The minimum inhibitory concentration of A22 and the minimum concentration to induce coccoid forms for various pathogenic bacteria were determined. At $10 \mu \mathrm{g} / \mathrm{ml}, \mathrm{A} 22$ induced coccoid forms in Shigella flexneri but did not inhibit the growth. No alteration of coccoid forms in the Gram-positive bacteria and anaerobic bacteria tested were observed following treatment with A22. To study the relationship between pathogenicity and alterations in bacterial shape, the infectious capacity of A22-induced coccoid $S$. flexneri was examined using CHO-K1 cells. Invasion of the coccoid cells was significantly reduced, however, no changes in adherence were observed. Using a mutant defective in the type III secretion apparatus, which delivers effectors to the host, we examined the secretion of effectors by A22-induced coccoid $S$. flexneri. The amount of secreted effectors in the coccoid cells was clearly decreased compared to rod-shaped cells. These results showed that the maintenance of rod-shaped cells by MreB in bacteria was essential for the secretion of effectors via the type III secretion system. Therefore, our results suggest that $\mathrm{A22}$ is a useful lead compound for a novel antiinfectious agent without bactericidal activity and MreB is a candidate target site for development of new antiinfectious agents.
\end{abstract} system

Key words anti-infectious agent; MreB; S-benzylisothiourea compound A22; Shigella flexneri; coccoid form; type III secretion

Various antibacterial agents have been developed and used for the treatment and prevention of infectious diseases. These drugs show antibacterial activity by inhibiting growth or directly killing bacteria. This antibacterial activity induces the microbial substitution and the emergence of drug-resistant bacteria. ${ }^{1)}$ Therefore, improper use of antibacterial agents selects for drug-resistant bacteria and increases their prevalence. To prevent this problem, it is necessary to develop therapeutic agents that are fundamentally different from current antibacterial agents. ${ }^{2)}$

It is possible that prevention or blockage of bacterial infections could be achieved by interfering with the adherence and/or the invasion of bacteria in host cells. The type III secretion apparatus, one of the virulence factors in bacteria, is necessary for the invasion of pathogenic bacteria into host cells. $^{3-5)}$ Preventing the function of the type III secretion apparatus can attenuate the infectious capacity of pathogenic bacteria, including Yersinia ${ }^{6}$ and Chlamydia, ${ }^{7)}$ without actually killing of the bacteria. Therefore, the type III apparatus has been considered a candidate target site for the development of new antibacterial agents. ${ }^{8,9)}$

Actin-like protein, MreB, which serves a cytoskeletal function, is necessary for maintenance of the rod-shape of bacteria, including Escherichia coli and Bacillus subtilis. ${ }^{10-12)}$ Furthermore, MreB is associated with chromosome segregation and protein localization to the cell poles. $^{13-15)} S$-(3,4-Dichlorobenzyl)isothiourea (A22), which was discovered as an inhibitor of replication in $E$. coli, inhibits the function of MreB by binding to MreB and transforming rod-shaped bacterial cells into coccoid forms. ${ }^{13,16)}$ A22 has a bacteriostatic effect on certain Gram-negative bacilli, including E. coli. ${ }^{16)}$
Shigella spp., which are Gram-negative rod-shaped bacteria, are some of the causative agents of bacillary dysentery. ${ }^{17)}$ Via oral ingestion, Shigella reaches the colon and invades the intestinal epithelial cells, causing destruction of the epithelial layer. The type III secretion system is necessary for the invasion of Shigella into epithelial cells and it delivers effectors directly into host cells. ${ }^{17,18)}$ The secreted effectors identified in $S$. flexneri are virulence factors for host cells and various type III effectors, including IpaA, IpaB, IpaC, IpaD, IpgD, and VirA. ${ }^{18-20)}$ Type III secretion systems are not found in non-pathogens. Furthermore, in addition to the type III secretion system, the rod-shape of Shigella seems likely to be necessary for the invasion of host cells because the shape of the cells is linked to the polar localization of certain proteins, including IcsA. ${ }^{15,21)}$

In this study, the antibacterial activity of A22 was determined, in addition to its coccoid form-inducing effects. Furthermore, the infectious capacity and effector secretion of A22-induced coccoid Shigella cells were examined. We suggest the utility of A22 as a lead compound for generating new anti-infectious drugs and the possibility of MreB as a new target site for development of antibacterial agents.

\section{MATERIALS AND METHODS}

Bacterial Strains and Chemicals The strains used in MIC determination are shown in Table 1. Shigella flexneri IID642 was grown on Brain Heart Infusion (BHI, OXOID Ltd., Basingstoke, U.K.) and Tryptone Soya agar (TSA, Oxoid). S. flexneri S325, a mutant defective in the type III secretion apparatus, was used as a reference strain for the analysis of effector secretion. ${ }^{22)}$ Chinese hamster ovary 
Table 1. Antibacterial Susceptibility and Coccoid form Inducing Effect of A22 for Various Bacteria

\begin{tabular}{lrrr}
\hline \hline \multicolumn{1}{c}{ Microorganism } & $\mathrm{mreB}$ & $\mathrm{MIC}^{a)}$ & $\mathrm{MCIC}^{b)}$ \\
\hline Staphylococcus aureus ATCC29213 & - & $\geq 256$ & $\mathrm{ND}^{c)}$ \\
Bacillus subtilis ATCC6633 & + & $\geq 256$ & $\geq 256$ \\
Escherichia coli ATCC25922 & + & 4 & 32 \\
Escherichia coli O157:H7 1095 & + & 4 & 32 \\
Salmonella Typhimurium ATCC14028 & + & 4 & 32 \\
Salmonella Enteritidis PTI-93-417 & + & 4 & 32 \\
Shigella flexneri IID642 & + & 128 & 4 \\
Klebsiella pneumoniae ATCC13882 & + & 128 & $\geq 256$ \\
Serratia marcescens ATCC8100 & + & 128 & $\geq 256$ \\
Pseudomonas aeruginosa ATCC27853 & + & 64 & 32 \\
Vibrio cholerae E9 & + & 4 & 2 \\
Helicobacter pylori ATCC43504 & + & $\geq 256$ & $\geq 256$ \\
Clostridium sporogenes ATCC11437 & + & 128 & $\geq 256$ \\
Micromonas micros GAI5540 & + & 128 & $\geq 256$ \\
Porphyromonas gingivalis JCM8525 & + & 128 & $\geq 256$ \\
Propionibacterium acnes JCM6425 & + & 128 & $\geq 256$ \\
Streptococcus intermedius GAI7416 & - & 128 & $\mathrm{ND}^{c)}$ \\
Bacteroides vulgatus JCM5826 & + & 128 & $\geq 256$ \\
Tannellela forsythensys JCM10827 & + & 128 & $\geq 256$ \\
Leptospira biflexa PatocI & + & $\geq 256$ & 16 \\
& & &
\end{tabular}

a) MIC, minimum inhibitory concentration $(\mu \mathrm{g} / \mathrm{ml})$. b) MCIC, minimum coccoidform inducing concentration $(\mu \mathrm{g} / \mathrm{ml})$. c) $\mathrm{ND}$, not determined.

(CHO-K1) cells, provided by RIKEN Bioresource Center (Ibaraki, Japan), were used as host cells in the invasion experiment and were grown in Eagle minimal essential medium (MEM, Nissui Pharmaceutical Co., Ltd., Tokyo, Japan) containing 5\% fetal bovine serum (BioWest, France).

MIC Determination Susceptibility testing was performed using agar dilution and broth microdilution methods according to the guidelines established by the Clinical and Laboratory Standards Institute (CLSI). ${ }^{23)}$ Microaerophilic and anaerobic bacteria were grown on Muller-Hinton (MH) agar (Oxoid) containing 5\% horse blood and BHI containing $5 \%$ sheep blood, respectively. Vibrio parahaemolyticus was grown using $\mathrm{MH}$ medium containing $2 \% \mathrm{NaCl}$. MIC of Leptospira biflexa was determined by a broth microdilution method using Korthof medium at $30^{\circ} \mathrm{C}$ for $5 \mathrm{~d}^{24)}$ The minimum concentration of $S$-benzylisothiourea compound (A22) required for conversion into approximately $>80 \%$ of coccoid forms from rod-shaped cells was defined as the minimum coccoid form-inducing concentration (MCIC) according to the MIC test. Formation of coccoid cells was observed in liquid culture medium or on the agar plate from the MIC test using a phase-contrast microscope. The MCIC of Leptospira was defined as a minimum concentration where no spiral forms were detected because a portion of the Leptospira cells changed into coccoid forms during incubation.

Adherence Assay The adhesive properties of $S$. flexneri to $\mathrm{CHO}-\mathrm{K} 1$ cells were determined using a modified method published by Willer et al. ${ }^{25)}$ Coccoid $S$. flexneri were prepared by incubation in BHI broth containing $10 \mu \mathrm{g} / \mathrm{ml}$ of A22 at $37^{\circ} \mathrm{C}$ until the bacteria reached the mid-log-phase. In order to prevent invasion of the bacteria into $\mathrm{CHO}-\mathrm{K} 1$ cells, chloramphenicol $(20 \mu \mathrm{g} / \mathrm{ml})$ was added to the bacterial culture, and the culture was incubated for $30 \mathrm{~min}$. Coccoid $S$. flexneri were washed in phosphate buffered saline (PBS) and collected by centrifugation $(2500 \times \boldsymbol{g}, 20 \mathrm{~min})$. The bacterial pellet was resuspended to a concentration of approximately $4 \times 10^{7}$ cells $/ \mathrm{ml}$ in MEM containing A22. CHO-K1 cells at
$4 \times 10^{5}$ cells $/ \mathrm{ml}$ were infected with the above mentioned coccoid $S$. flexneri $(\mathrm{MOI}=100)$ by a $3 \mathrm{~h}$ incubation at $37^{\circ} \mathrm{C}$ in $5 \% \mathrm{CO}_{2}$ atmosphere. Subsequently, the culture was washed eight times using Hanks solution (Nissui Pharmaceutical Co., Ltd., Tokyo, Japan), and permeabilization was done using 1\% Triton X-100 (Wako Pure Chemical Industries, Ltd., Osaka, Japan) for $5 \mathrm{~min}$ at room temperature. The floating bacteria were appropriately diluted and spread on TSA. After incubation at $37^{\circ} \mathrm{C}$ for $24 \mathrm{~h}$, the colonies on TSA were counted, and the number of $S$. flexneri that adhered to $\mathrm{CHO}$ cells was calculated.

Invasion Assay The invasive properties of $S$. flexneri to CHO-K1 cell were determined using a gentamicin-protection assay. ${ }^{26,27)}$ The preparation of CHO-K1 cells and coccoid $S$. flexneri was carried out as described above. Coccoid $S$. flexneri (approximately $10^{7}$ cells) were added to $\mathrm{CHO}$ cells (approximately $10^{5}$ cells), and infection $(\mathrm{MOI}=100)$ was done with a $5 \mathrm{~h}$ incubation at $37^{\circ} \mathrm{C}$ in $5 \% \mathrm{CO}_{2}$ atmosphere. The culture was washed three times using PBS, and the extracellular bacteria were killed by incubation in MEM containing $100 \mu \mathrm{g} / \mathrm{ml}$ gentamicin (Wako Pure Chemical Industries, Ltd., ${ }^{28,29)}$ Osaka, Japan) for $1 \mathrm{~h}$ at $37^{\circ} \mathrm{C}$ in $5 \% \mathrm{CO}_{2}$ atmosphere. The $\mathrm{CHO}$ cells were washed six times using PBS and permeabilization was performed as described above. The floating bacteria in PBS was diluted and spread on TSA. After incubation at $37^{\circ} \mathrm{C}$ for $24 \mathrm{~h}$, colonies were counted. Efficiency of invasion was expressed as follows: (number of intracellular bacteria-blank) $\times 100 /$ (number of extracellular bacteria). Efficiency of invasion for $S$. flexneri into $\mathrm{CHO}-\mathrm{K} 1$ cells was determined in triplicate in five independent experiments.

Analysis of Protein Secretion $S$. flexneri were incubated in BHI broth with or without A22 $(10 \mu \mathrm{g} / \mathrm{ml})$ for $4 \mathrm{~h}$ at $37^{\circ} \mathrm{C}$. The whole cell lysates and Congo red-induced supernatants of $S$. flexneri were prepared as described by Tamano et $a .^{20,29)}$ Intracellular proteins and effector were analyzed using Sodium Dodecyl Sulfate (SDS)-polyacrylamide gel electrophoresis. $^{20,30)}$ The fragment corresponding to the effector was analyzed using Scion Image Beta 4.0.3.

Statistical Analysis Significance of the infectious capacity of $S$. flexneri to CHO-K1 cells with or without A22 was calculated by the $\chi^{2}$ test, with $p$ values of $<0.05$ considered to be statistically significant.

\section{RESULTS}

Antibacterial and Coccoid Form-Inducing Activities of A22 The MIC of A22 for various pathogenic bacteria was determined (Table 1). A22 showed antibacterial activity for E. coli strains, Salmonella spp., $P$. aeruginosa, and $V$. cholerae. The MIC of A22 for Gram-positive bacteria, $S$. flexneri, Helicobacter pylori, anaerobic bacteria, and Leptospira was $\geq 128 \mu \mathrm{g} / \mathrm{ml}$. Although the MIC of A22 for $E$. coli was determined under both microaerophilic and anaerobic conditions, no differences were observed (data not shown).

Furthermore, the morphological changes in bacteria on the A22 MIC-determining plates were observed using phase contrast microscopy. The minimum concentration of A22 necessary to induce coccoid forms from rod-shaped cells (MCIC) was also determined (Table 1). In $S$. flexneri, $P$. 
aeruginosa, $V$. cholerae, and L. biflexa, the MCICs of A22 were lower than the MICs (Fig. 1). No coccoid forms were observed in Enterobacteriaceae, excluding $S$. flexneri at A22 concentrations lower than the MIC. When morphological alterations of E. coli and Salmonella were observed following the addition of a serial two-fold concentration of A22 at mid$\log$-phase, coccoid bacteria were found at a higher A22 concentration $(32 \mu \mathrm{g} / \mathrm{ml})$ than the MICs. When A22 was removed from cultures of coccoid $E$. coli and $S$. flexneri, after incubation of $2 \mathrm{~h}$, the coccoid forms returned to native rodshaped forms (data not shown). This result showed that the action of A22 on MreB was reversible. On the other hand, no effect of A22 was observed in microaerophilic or anaerobic bacteria (Fig. 1).

In the bacteria tested, $S$. flexneri, which is a typical pathogenic bacterium, changed to the coccoid forms by A22 concentration lower than the MIC. To study the viability of A22induced coccoid bacteria, the growth of $S$. flexneri was examined in the presence of A22 $(10 \mu \mathrm{g} / \mathrm{ml})$. Although a small reduction in the growth rate of $S$. flexneri was observed following the addition of A22, coccoid $S$. flexneri was propagated until the stationary phase (Fig. 2). Therefore, a small amount of A22 (4 $\mu \mathrm{g} / \mathrm{ml})$, which was lower than the MIC, was able to induce the coccoid form of $S$. flexneri. However, A22 had antibacterial activity for some aerobic and facultative anaerobic gram-negative bacteria.

Effect of Reducing Cell Invasion with A22 To study the possibility of using A22 as an anti-infectious compound, the infectious capacity of A22-induced coccoid $S$. flexneri was examined. Since the first step in infection is adherence of bacteria to host cells, we measured the adhesive properties of the coccoid $S$. flexneri to CHO-K1 cell (Fig. 3). No significant difference in adhesion to $\mathrm{CHO}-\mathrm{K} 1$ cell between coccoid
A

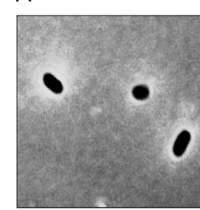

0

C

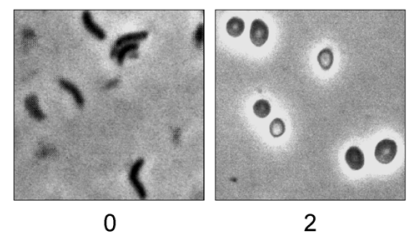

E

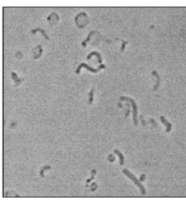

0

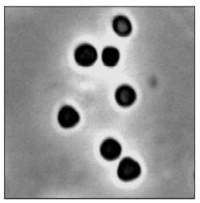

4

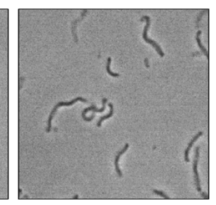

128

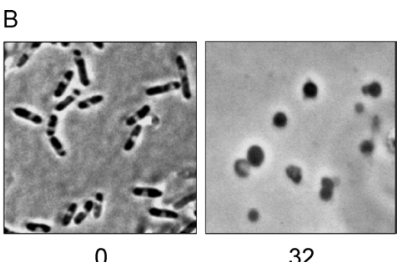

D

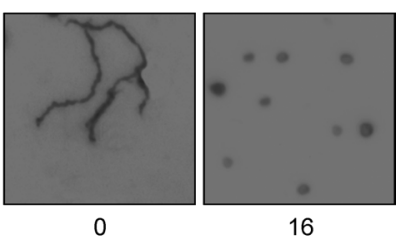

F

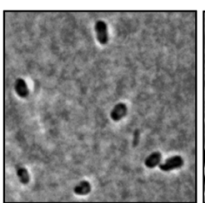

0

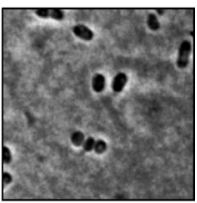

128

Fig. 1. Morphological Alterations of Gram-Negative Bacilli by A22

Phase contrast microscope photographs of bacteria after treatment with A22 for $6 \mathrm{~h}$ (A) Shigella flexneri IID642; (B) Pseudomonas aeruginosa ATCC27853; (C) Vibrio cholerae E9; (D) Leptospira biflexa PatocI; (E) Helicobacter pylori ATCC43504; (F) Bacteroides vulgatus JCM5826. The numerical value under the photograph shows the concentration of A22 $(\mu \mathrm{g} / \mathrm{ml})$.

and native $S$. flexneri was observed. Subsequently, the invasive ability of the coccoid $S$. flexneri to $\mathrm{CHO}$ cells was measured in the presence of $1,2.5,5,10$, and $20 \mu \mathrm{g} / \mathrm{ml}$ of A22 each by a gentamicin protection assay (Fig. 4). Morphological alteration of $S$. flexneri to coccoid form in the presence of the above-mentioned concentrations of A22 was confirmed using phase contrast microscopy. The invasion rates of $S$. flexneri into CHO-K1 cells were decreased in $63.3 \%, 66.9 \%$ $15.6 \%, 2.8 \%$, and $2.7 \%$ following the additions of $1,2.5,5$, 10 , and $20 \mu \mathrm{g} / \mathrm{ml}$ of $\mathrm{A} 22$, respectively. These results demonstrated that when the concentration range that was lower than the MIC, A22 inhibited the invasion of $S$. flexneri into $\mathrm{CHO}$ cells in a dose-dependent manner. However, A22 was not effective in reducing the adherence of bacteria to the host cells.

Analysis of Secreted Proteins in Coccoid $S$. flexneri The change in total protein in A22-induced coccoid $S$. flexneri was studied using SDS-PAGE (data not shown). No remarkable differences were observed between the total intracellular proteins of the coccoid form and native rodshaped cells. These results showed that A22 had no influence on the synthesis of major intracellular proteins in the coccoid

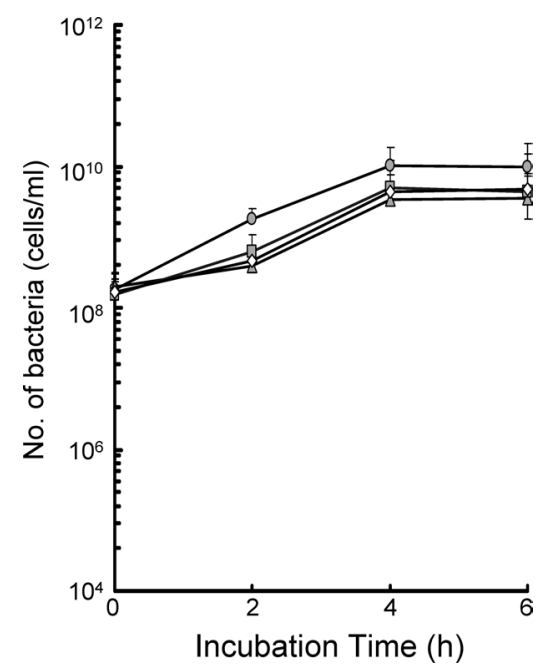

Fig. 2. Growth of $S$. flexneri in the Absence or Presence of A22. $S$. flexneri Was Incubated in BHI Broth with Shaking at $37^{\circ} \mathrm{C}$ in the Absence (Circle) and Presence of $5 \mu \mathrm{g} / \mathrm{ml}$ (Square), $10 \mu \mathrm{g} / \mathrm{ml}$ (Diamond) and $20 \mu \mathrm{g} / \mathrm{ml}$ (Triangle) of A22

The number of viable cells was measured by the colonies grown on TSA by the spread of appropriately diluted culture. Growth and cell counts were measured in three independent experiments.

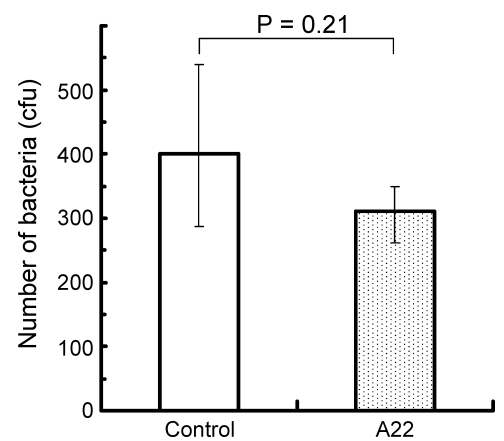

Fig. 3. Effect on Adherence of Coccoid S. flexneri to CHO Cells Induced by A22

S. flexneri was incubated in the presence of $10 \mu \mathrm{g} / \mathrm{ml}$ of A22. These data represent the statistical mean \pm standard deviations of four independent experiments. 


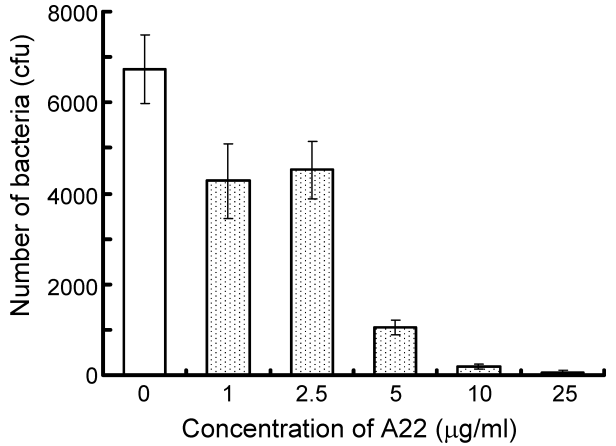

Fig. 4. Inhibitory Effect of A22 on the Invasion of S. flexneri into CHOK1 Cells

These data represent the statistical mean \pm standard deviations of ternary in five independent experiments.

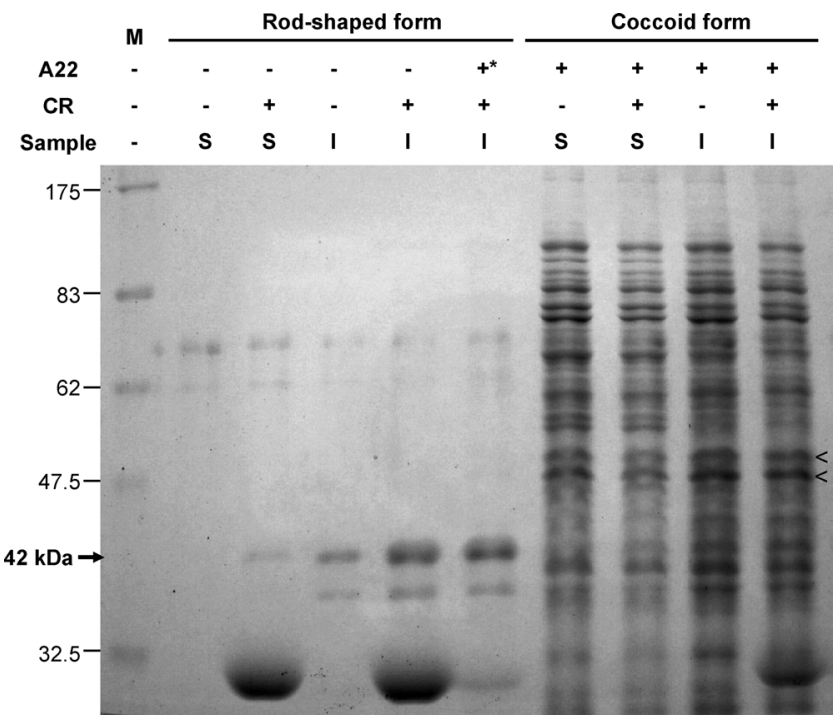

Fig. 5. Inhibitory Effect on Effector Secretion by A22 in S. flexneri

The rod-shaped form was native $S$. flexneri and the coccoid form of $S$. flexneri was prepared by incubation in BHI containing $10 \mu \mathrm{g} / \mathrm{ml}$ of A22 at $37^{\circ} \mathrm{C}$ for $4 \mathrm{~h}$. M, prestained protein marker; S, S. flexneri $\mathrm{S} 325$ mutant defective in the type III secretion apparatus; I, S. flexneri IID642; CR, Congo-red; A22, A22 compound; +*, A22 was added simultaneously with Congo-red. $<$, intracellular proteins used as the internal standard. The numerical value shows molecular weight $(\mathrm{kDa})$.

S. flexneri. Alterations in the extracellular level of secreted effector, which was essential for invasion of S. flexneri into host cells, was examined by the addition of Congo-red (Fig. 5). In native rod-shaped S. flexneri, the amount of effector secreted following stimulation with Congo-red was elevated both in the presence and absence of A22. These results indicated that A22 did not directly inhibit either the secretion or the production of effector (Fig. 5). However, no increase in effector secretion was induced by Congo-red in coccoid $S$. flexneri or in the S325 mutant strain defective in the type III secretion apparatus (Fig. 5). Additionally, the amount of effector secreted from coccid $S$. flexneri was determined with various concentrations of A22, using two intracellular proteins as the internal standard (Fig. 6). Although the effector level of native $S$. flexneri could not be estimated because no intracellular protein was detected, effector secretion was decreased in a dose-dependent manner with $\mathrm{A} 22$ up to the MCIC $(4 \mu \mathrm{g} / \mathrm{ml})$. No decrease in effector secretion was observed for A22 concentrations higher than the MCIC. These results showed that the conversion to the coccoid form of $S$.

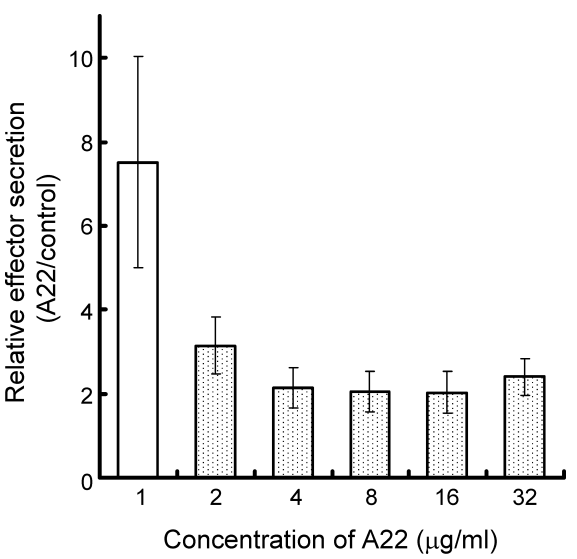

Fig. 6. Relative Amount of Effector Secreted from Coccoid S. flexneri Induced by Various Concentrations of A22

The intensity of the effector band on SDS-PAGE was calculated by using a suitable intracellular protein bands (Fig. 5) as an internal standard. These data represent the statistical mean \pm standard deviations of five independent experiments.

flexneri induced by A22 led to a decrease in effector secretion. Most likely, A22 transformed rod-shaped S. flexneri into coccoid forms by binding to the actin-like protein, MreB, and the blockade of effector secretion in the coccoid form led to the inhibition of cell-invasion by $S$. flexneri.

\section{DISCUSSION}

In the present study, we examined the utility of A22 as an anti-infectious agent. It induced conversion to the coccoid form from rod-shaped bacteria by inactivating MreB and also induced conversion to the coccoid form of some aerobic and facultative anaerobic Gram-negative bacilli. Vegetative rodshaped cells rapidly changed to coccoid forms in the presence of concentrations of A22 greater than the MCIC, although the coccoid form was rarely observed at A22 concentrations less than the MCIC (data not shown). In E. coli, Salmonella spp., $V$. cholerae, and $P$. aeruginosa, the MICs were lower than the MCICs. The antibacterial action of A22 was bacteriostatic $^{16)}$ and $E$. coli could live in the presence of $>256 \mu \mathrm{g} / \mathrm{ml}$ of A22 (data not shown). S. flexneri transformed from rod-shaped to coccoid forms at lower concentration of A22 (MCIC: $4 \mu \mathrm{g} / \mathrm{ml})$ than the MIC $(128 \mu \mathrm{g} / \mathrm{ml})$. The viable cell number of $S$. flexneri was slightly lower than that estimated from absorbance density at $600 \mathrm{~nm}$ in this study, as A22 induced the production of minicells. ${ }^{16)}$ The colony forming S. flexneri cells were counted using the TSB plates. Although the growth rate of the A22-induced coccoid $S$. flexneri was slightly decreased compared to native S. flexneri, the coccoid cells grew in the presence of $20 \mu \mathrm{g} / \mathrm{ml}$ of A22 until the stationary phase. These results suggest that A22 inhibits the functions of the actin-like protein, MreB, in $S$. flexneri, but might not block the chromosome segregation, even though it was blocked in E. coli. ${ }^{13,14)}$ On the other hand, the MIC and MCIC of Gram-positive bacteria, microaerophilic bacteria, and anaerobic bacteria were $\geq 128$ $\mu \mathrm{g} / \mathrm{ml}$. MreB in H. pylori and Bacillus spp. has a different amino acid sequence in the binding region of A22 compared to Gram-negative bacteria including E. coli. ${ }^{31-33)}$ Therefore, the differences in the antibacterial spectrum of A22 may be due to diversity in the amino acid sequence of the binding re- 
gion of A22 in MreB.

Since $S$. flexneri is a major invasive bacterium and its growth was not inhibited by A22, we studied cell adherence and invasion of A22-induced coccoid S. flexneri. Although no significant difference in cell adherence capacity was observed between the A22-induced coccoid form and native $S$. flexneri, the cell invasion rate of $S$. flexneri rapidly decreased in the presence of $5 \mu \mathrm{g} / \mathrm{ml}$ of A22. The decrease in invasion rate at A22 concentration greater than MCIC was gradual. The transformation to the coccoid form was increased in the presence of A22 concentrations greater than the MCIC. These results suggest that the inhibition of cell invasion by $S$. flexneri is attributable to the morphological change induced by the inactivation of MreB by A22.

Furthermore, we examined effector levels secreted via the type III secretion system, which was essential for the cell invasion of $S$. flexneri, as no changes in intracellular proteins between the native and coccoid $S$. flexneri were observed by SDS-PAGE. Rod-shaped S. flexneri were separated by centrifugation followed by membrane filteration (pore size: $0.45 \mu \mathrm{m})$. The coccoid cells passed through the membrane filter and the SDS-PAGE sample was contaminated with the intracellular proteins from the coccoid cells. Although we tried to separate the coccoid cells by filtration through filters with small pore sizes, these cells could not be sufficiently remove from the culture (data not shown). Accordingly, a mutant with a defective type III secretion apparatus was used for the examination of the effector secretion from coccoid cells. When effector secretion from coccoid $S$. flexneri was induced by Congo-red, a decrease in the secretion of $42-\mathrm{kDa}$ effector was observed (Fig. 5). The reduced $42-\mathrm{kDa}$ protein(s) corresponded to IpaC $(42 \mathrm{kDa})$ and VirA $(44.7 \mathrm{kDa})$, among the effectors of $S$. flexneri. ${ }^{34,35)}$ Furthermore, experiments where A22 and Congo-red were added simultaneously to a culture of rod-shaped $S$. flexneri (Fig. 5) showed that A22 did not directly inhibit effector secretion when the amount of the secreted effector(s) was determined (Fig. 6). Therefore, our results suggest that the inhibition of the cell invasion by $S$. flexneri is due to a blockade of effector secretion, including IpaC or VirA, by the morphological transformation of rodshaped $S$. flexneri into coccoid form by A22. The mechanism of the decrease in effector secretion from coccoid $S$. flexneri has been unclear. Some intracellular proteins are incorrectly localized in the A22-induced coccoid form ${ }^{15,21)}$ and this mislocalization may be related to the decrease in effector secretion. Further studies of the decrease in effector secretion caused by A22 are needed.

In this study, our results showed that actin-like protein, $\mathrm{MreB}$, an essential protein for the maintenance of a rodshape in bacteria, was associated with effector secretion mediated by the type III secretion system. Some pathogenic bacteria, including Salmonella and enterohemorrhagic $E$. coli, which also have a type III secretion system, were transformed into coccoid forms by A22 but higher A22 concentrations than the MIC was required. In addition, $H$. pylori carrying a type III secretion system did not take on a coccoid form following A22 treatment. However, it might be possible to develop a compound that is able to change pathogenic rodshaped bacteria into coccoid forms by the synthesizing various derivatives of A22, ${ }^{36,37)}$ as well as developing other antimicrobial agents. Furthermore, the major antimicrobial agents have bactericidal or bacterial growth inhibition activity. The lysis of bacterial cells by antimicrobial agents may release endotoxin and exotoxin, including verotoxin. In addition, antimicrobial agents can lead to the emergence of the drug-resistant strains by the selective pressure of the drug and the killing of susceptible strains. The antibacterial activity of A22 was small and the removal of A22 led to the recovery of coccoid cells to native rod-shaped cells. Consequently, our study suggests that A22 is a useful lead compound for novel anti-infectious agents without bactericidal activity and MreB is a new candidate target site for the development of anti-infectious agents.

Acknowledgements We thank Dr. C. Sasakawa of Institute of Medical Science and University of Tokyo for providing $S$. flexneri S325. We also thank Dr. T. Masuzawa (Laboratory of Microbiology and Immunology, Faculty of Pharmaceutical Sciences, Chiba Institute of Science, Chiba, Japan) for providing us with Leptospira biflexa. This work was supported by the High-Tech Research Centre Project for Private Universities provided by the Ministry of Education, Culture, Sports, Science and Technology; and by the Matching Fund Subsidy for Private Schools of Japan.

\section{REFERENCES}

1) Normark B. H., Normark S., J. Intern. Med., 252, 91-106 (2002).

2) Lee Y. M., Almqvist F., Hultgren S. J., Curr. Opin. Pharmacol., 3, 513-519 (2003)

3) Cornelis G. R., Van Gijsegem F., Annu. Rev. Microbiol., 54, 735-774 (2000).

4) Hueck C. J., Microbiol. Mol. Biol. Rev., 62, 379-433 (1998).

5) Mota L. J., Sorg I., Cornelis G. R., FEMS Microbiol. Lett., 252, $1-10$ (2005).

6) Nordfelth R., Kauppi A. M., Norberg H. A., Wolf-Watz H., Elofsson M., Infect. Immun., 73, 3104-3114 (2005).

7) Muschiol S., Bailey L., Gylfe A., Sundin C., Hultenby K., Bergstrom S., Elofsson M., Wolf-Watz H., Normark S., Henriques-Normark B. Proc. Natl. Acad. Sci. U.S.A., 103, 14566-14571 (2006).

8) Gauthier A., Finlay B. B., ASM News, 68, 383-387 (2002).

9) Muller S., Feldman M. F., Cornelis G. R., Expert Opin. Ther. Targets, 5, 327-339 (2001).

10) Amos L. A., van den Ent F., Lowe J., Curr. Opin. Cell Biol., 16, 24 31 (2004).

11) Carballido-Lopez R., Mol. Microbiol., 60, 815-819 (2006).

12) Figge R. M., Divakaruni A. V., Gober J. W., Mol. Microbiol., 51, $1321-1332$ (2004)

13) Gitai Z., Dye N. A., Reisenauer A., Wachi M., Shapiro L., Cell, 120, $329-341$ (2005).

14) Kruse T., Blagoev B., Lobner-Olesen A., Wachi M., Sasaki K., Iwai N., Mann M., Gerdes K., Genes Dev., 20, 113-124 (2006).

15) Nilsen T., Yan A. W., Gale G., Goldberg M. B., J. Bacteriol., 187, $6187-6196$ (2005).

16) Iwai N., Nagai K., Wachi M., Biosci. Biotechnol. Biochem., 66, 2658-2662 (2002).

17) Jennison A. V., Verma N. K., FEMS Microbiol. Rev., 28, 43-58 (2004).

18) Sansonetti P. J., FEMS Microbiol. Rev., 25, 3-14 (2001).

19) Handa Y., Suzuki M., Ohya K., Iwai H., Ishijima N., Koleske A. J., Fukui Y., Sasakawa C., Nat. Cell Biol., 9, 121-128 (2007).

20) Ogawa M., Suzuki T., Tatsuno I., Abe H., Sasakawa C., Mol. Microbiol., 48, 913-931 (2003).

21) Gitai Z., Dye N., Shapiro L., Proc. Natl. Acad. Sci. U.S.A., 101, 8643 -8648 (2004).

22) Sasakawa C., Makino S., Kamata K., Yoshikawa M., Infect. Immun., 54, 32-36 (1986)

23) Clinical and Laboratory Standards Institute (CLSI), "Methods for dilution antimicrobial susceptibility tests for bacteria that grow aerobi- 
cally," 7th ed., Vol. approved standard M7-A7. Clinical and Laboratory Standards Institute, Wayne, PA, 2007.

24) Oie S., Hironaga K., Koshiro A., Konishi H., Yoshii Z., Antimicrob Agents Chemother, 24, 905-908 (1983).

25) Willer Eda M., Lima Rde L., Giugliano L. G., BMC Microbiol., 4, 18 (2004).

26) Small P. L., Isberg R. R., Falkow S., Infect. Immun., 55, 1674-1679 (1987).

27) Ewanowich C. A., Sherburne R. K., Man S. F., Peppler M. S., Infect. Immun., 57, 1240-1247 (1989).

28) Bahrani F. K., Sansonetti P. J., Parsot C., Infect. Immun., 65, 40054010 (1997)

29) Tamano K., Aizawa S., Katayama E., Nonaka T., Imajoh-Ohmi S., Kuwae A., Nagai S., Sasakawa C., EMBO J., 19, 3876-3887 (2000).

30) Noguchi N., Takada K., Katayama J., Emura A., Sasatsu M., J. Bacte- riol., 182, 5052-5058 (2000).

31) Bork P., Sander C., Valencia A., Proc. Natl. Acad. Sci. U.S.A., 89, 7290-7294 (1992).

32) Jones L. J., Carballido-Lopez R., Errington J., Cell, 104, 913-922 (2001).

33) van den Ent F., Amos L. A., Lowe J., Nature (London), 413, 39-44 (2001).

34) Demers B., Sansonetti P. J., Parsot C., EMBO J., 17, 2894-2903 (1998).

35) Uchiya K., Tobe T., Komatsu K., Suzuki T., Watarai M., Fukuda I., Yoshikawa M., Sasakawa C., Mol. Microbiol., 17, 241-250 (1995).

36) Iwai N., Ebata T., Nagura H., Kitazume T., Nagai K., Wachi M., Biosci. Biotechnol. Biochem., 68, 2265-2269 (2004).

37) Iwai N., Fujii T., Nagura H., Wachi M., Kitazume T., Biosci. Biotechnol. Biochem., 71, 246-248 (2007). 